\title{
¿CÓMO ENTENDER AL OTRO? MULTILINGÜISMO Y TRANSLINGÜISMO EN LA ROAD MOVIE LATINOAMERICANA
}

\author{
Nadia Lie ${ }^{1}$ \\ ${ }^{1}$ Katholieke Universiteit Leuven, Leuven, Flandres, Belgium
}

\begin{abstract}
Resume: Este artículo examina uno de los aspectos menos explorados del género de la road movie: su dimensión lingüística. Se presentan en primer lugar los rasgos específicos de la variante latinoamericana del género con el fin de explicar por qué la lengua ocupa un lugar central en muchas narrativas de viaje. Se demuestra esta centralidad primero a contrario, presentando el caso de "mutismo" de personajes. Después se proponen dos modalidades básicas en las que la road movie reflexiona sobre la cuestión lingüística. En la primera, - el multilingüismo -, el punto de partida es la voluntad de comunicación por parte de personajes que se expresan en lenguas diferentes, pero el resultado final es una forma de incomunicación. En la segunda, - el translingüismo -, se produce la situación opuesta: se parte del reconocimiento de la diferencia radical de dos idiomas pero el resultado es, sin embargo, la comunicación. El texto argumenta que estas dos últimas modalidades ejemplifican la ambivalencia del acto comunicativo en sí, vinculándose respectivamente con una visión particularista y otra universalista acerca de la lengua.
\end{abstract}

Palabras-clave: Road Movie; Lengua; América Latina; Alteridad

\section{HOW TO UNDERSTAND THE OTHER? MULTILINGUALISM AND TRANSLINGUALISM IN THE LATIN AMERICAN ROAD MOVIE}

Abstract: This article examines language as an understudied aspect of the road movie idiom. After a brief sketch of the specific features of the Latin American road movie, it explains why language occupies a central place in 
many of its stories. First, attention is paid to cases in which this centrality is expressed a contrario by depicting characters who hardly express themselves (a strategy referred to as "mutism"). Subsequently, the article distinguishes between two basic ways in which road movies deal with language: multilingualism and translingualism. It uses the first term to refer to situations in which road movie characters belonging to different linguistic communities make a serious attempt to understand each other, yet end up finding that they are not able to convey what they really mean. The second term is used for situations in which characters assume language barriers between them will be too high to allow true communication; however, in the end they discover they are able to communicate anyway. The article concludes that the two ways of dealing with language - illustrative of a particularist and a universalist view on language respectively -suggest the ambivalence of communication in general.

Keywords: Road Movie; Language; Latin America; Otherness

Desde hace un par de años se ha experimentado un verdadero boom en cuanto a publicaciones sobre la road movie (e.o. Duarte \& Corrigan; Gott \& Schiltz). Un factor importante es la internacionalización del género. Tradicionalmente asociada con los Estados Unidos - país marcado por territorios extensos y mitos fundadores relacionados con el viaje -la road movie fue concebida inicialmente como prolongación del western en tiempos modernos por la conquista simbólica del espacio, reemplazando los caballos por las motocicletas y los coches (Bertelsen). Además, el fuerte impacto que produjo la novela estadounidense On the road (1957) de Jack Kerouac sobre el imaginario del viaje - introduciendo el motivo de los buddies y el énfasis en la ruta antes que en el destino - aparecía como otra prueba más de la relación intrínseca entre la road movie y los Estados Unidos (Cohan \& Hark; Laderman). Sin embargo, en los últimos años se registra un cambio en la literatura académica sobre el tema, marcado por un claro reconocimiento de la dimensión intercultural de la road movie (Moser) y una revisión crítica de sus orígenes y antecedentes en un sentido europeo (Orgeron). Más fuerte todavía es la atención al florecimiento actual de la road movie a nivel global, especialmente en América Latina (Brandellero; Pinazza; Garibotto \& Pérez; Lie). Como género 
apto para plasmar momentos de crisis o de transformación social mediante narrativas de movilidad y desplazamiento (Cohan \& Hark 2), la road movie parece haber adquirido especial relevancia en nuestra era de globalización acelerada, caracterizada por una intensificación del movimiento a nivel planetario, tanto en la variante hedonista del turismo como en la más trágica de la migración indocumentada o de los refugiados.

En América Latina es particularmente llamativo el uso de la road movie como instrumento de investigación crítica de la globalización (Pinazza). Si en la road movie prototípica el imaginario de la ruta se ponía al servicio de una exploración del yo - como también lo indica el consumo de drogas en On the road o Easy Rider (Dennis Hopper 1969), por ejemplo -, la road movie latinoamericana está más orientada hacia el encuentro con grupos marginalizados o excluidos de la sociedad de la que provienen los protagonistas. Además, es frecuente que el viaje en las películas latinoamericanas se interrumpa durante gran parte de la diégesis o incluso se cancele desde el inicio, transformándose en objeto de ilusión y frustración en las mentes de los viajeros iniciales. Estas "counter-road movies" (Lie) apuntan a una tendencia más general en las road movies latinoamericanas que consiste en decelerar el ritmo del viaje. Esto facilita a su vez el encuentro durante el viaje diegético con personajes que pertenecen a otra clase social o grupo étnico que los buddies. Dos películas emblemáticas del género en América Latina ejemplifican este fenómeno: Diarios de motocicleta (Walter Salles) e Y tu mamá también (Alfonso Cuarón 2002). En ambas películas los protagonistas se desplazan en un vehículo motorizado para emprender un viaje placentero, de fines aventureros (Diarios de motocicleta) y hasta eróticos (Y tu mamá también). En ambos casos también, el viaje lleva por territorios poblados por personas con las que los protagonistas no solían tener mucho contacto: indígenas y campesinos. Si la película de Cuarón adopta un modo crítico al destacar la ignorancia y falta de interés por parte de los buddies con respecto a la realidad que les circunda, el filme de Salles se centra en el impacto que produce la realidad 
desconocida en su mente, sugiriendo la transformación de uno de ellos - el joven Ernesto Guevara - en el futuro revolucionario que será. Para el director de esta road movie, Walter Salles, el potencial del género para América Latina y otras partes del mundo radica precisamente en esta dimensión social:

Road movies are about what can be learned from the other, from those who are different. In a world that increasingly challenges these ideals, the importance of road movies as a form of resistance cannot be dismissed (Salles 70).

Pero, ¿cómo entender a ese Otro? Es aquí donde la cuestión de la lengua recibe una importancia crucial. Las 5 películas de carretera en que nos detendremos en este artículo ilustran las diferentes estrategias que adoptan las películas para tematizar la cuestión de la lengua como marcadora de diferencias culturales. Proceden de 4 países diferentes (Brasil, Argentina, México y Chile) y pertenecen al circuito transnacional, lo cual implica que también circulan fuera de América Latina. Son películas exhibidas ante todo en el circuito de los festivales de cine. Pero también en la película emblemática del género, Diarios de motocicleta, que se distribuyó más en el circuito de cine de arte comercial, se advierte la gran importancia de la lengua. Así, en una escena clave se enseña cómo el encuentro con quienes son diferentes de nosotros implica el encuentro con su lengua. En esta escena, situada en la mitad exacta de la película, se relata cómo Ernesto (Che) Guevara y su amigo Alberto, después de la ruptura de su vehículo, no tardan en encontrarse, como caminantes a pie, con un grupo de mujeres indígenas con quienes entablan una conversación. Al contestar preguntas sobre sus circunstancias de vida, la mujer más anciana del grupo usa la lengua quechua mientras otra mujer del grupo, un poco más joven, asegura la traducción al español. (fig. 1). ${ }^{1}$

\footnotetext{
${ }^{1}$ Agradezco a los directores de las películas el permiso de insertar imágenes de sus películas en este artículo con fines didácticos.
} 
Figura 1: Ernesto Guevara y Alberto Granado conversan con mujeres indígenas en Diarios de motocicleta

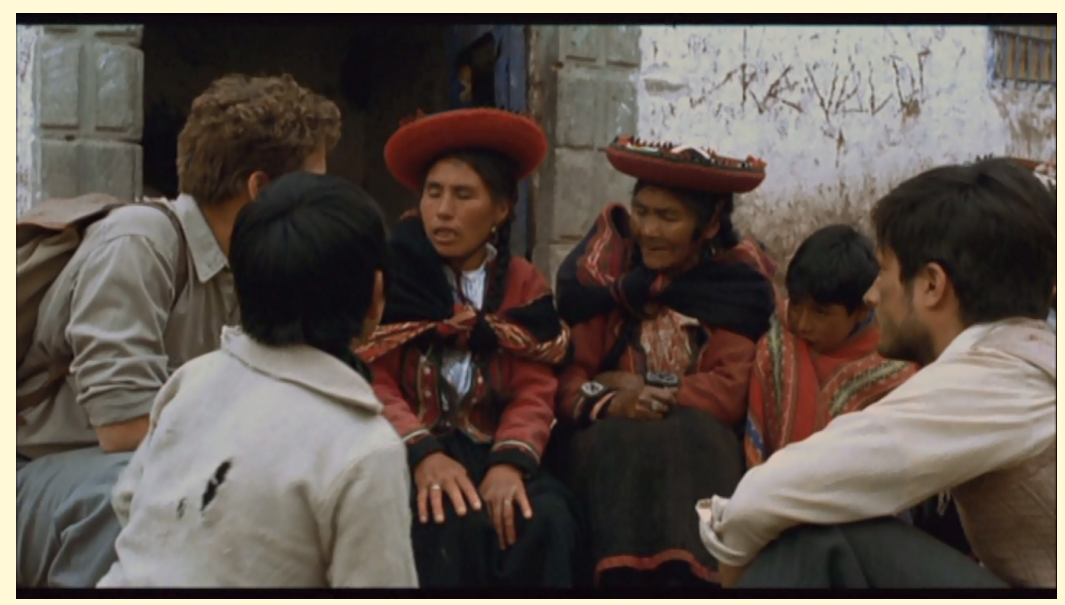

Fonte: Diarios de motocicleta.

A continuación la anciana inicia a los buddies en los ritos religiosos de los descendientes de la cultura inca, pronunciando fórmulas en quechua que ellos repiten literalmente y acompañándoles de gestos que Ernesto y su amigo imitan con el debido respeto. Lo que indica esta escena, situada en medio de la película y así en un lugar simbólicamente central, es que el quechua es más que un instrumento de comunicación o expresión: es una vía de acceso a otra cultura, otra manera de ver el mundo y el universo. Al utilizar para esta escena un estilo de filmar más cercano al documental que a una película de ficción (hand-held camera, conservación de los sonidos de trasfondo originales...), Salles sugiere además la actualidad de la cuestión de la lengua como marcadora de una diferencia cultural marginalizada.

Teniendo en cuenta la importancia que reviste la lengua para el encuentro con el Otro, es llamativa la casi total ausencia de comentarios sobre esta cuestión en la literatura académica sobre la road movie latinoamericana. Es posible que una concepción 
restringida acerca de la diversidad lingüística de América Latina - un continente dominado por el español y el portugués - explique esa falta de atención por parte de los académicos. También es cierto que el cine es un medio principalmente visual, por lo que los directores no siempre necesitan recurrir al idioma para comunicar un mensaje. Es más, la road movie como género pone especial énfasis en la dimensión visual del medio fílmico, ya que ver y mirar son actividades centrales de quien conduce. Tan es así que la voz de los personajes marginalizados queda a veces excluida del universo diegético. En lo que sigue me referiré a este fenómeno mediante el término de "mutismo".

\section{Mutismo}

En el caso del mutismo, los personajes marginalizados en la sociedad de su tiempo aparecen visualmente en la historia y reciben un papel diegético, pero no reciben (o solo raras veces) la posibilidad de expresarse de manera autónoma. Un ejemplo elocuente de esta estrategia discursiva se halla en la road movie brasileña Iracema. Uma transe amazónica (1975). Dirigida por Jorge Bodanzky y Orlando Senna, la película sigue a una adolescente de 15 años, de nombre Iracema, que al inicio del filme emerge de la selva amazónica y recorre gran parte del país en compañía de un camionero. Este camionero tiene unos treinta años y se presenta donde vaya con un apodo que él mismo se ha dado: Tião Brasil Grande. El apodo remite al sueño de la dictadura militar (1964-1985) de construir "un país grande" en estos años mediante la construcción de una extensa red automovilística que conectara el Norte con el Sur del país, y el Oeste con el Este. La construcción de estas autopistas tuvo consecuencias serias para la población local, la cual perdió sus terrenos a favor de rutas que sólo servían para los intereses de las grandes empresas en vez de conducir a un mejoramiento de sus condiciones de vida bastante miserables ( $e j$. falta de agua en muchas zonas) (Bael). Una 
secuencia en la película muestra además los estragos ecológicos causados por el proyecto, el cual implicaba el incendio sistemático de partes de la selva amazónica.

Ya que Tião atraviesa Brasil con su camión, se cruza con muchas personas afectadas directamente por el proyecto megalómano del régimen militar. Sin embargo, las conversaciones con estas personas nunca le llevan a revisar su opinión sobre las ambiciones de la dictadura: sigue repitiendo a quien quiera escucharlo que las obras de infraestructura aportarán progreso y desarrollo al país. Iracema le acompaña en el camino, disfrutando de un viaje gratuito (sin destino particular) a cambio de favores sexuales. Durante las conversaciones con la gente en el camino, la cámara a menudo enfoca su cara sugiriendo su afinidad con la gente afectada por las obras de construcción - gente pobre, habitante de estas zonas áridas y marginalizadas del Brasil. Sin embargo, nunca interviene en los debates sino que se limita a ser testigo de las discusiones. (fig.2)

Figura 2: Iracema escucha en silencio a Tião Brasil Grande defendiendo al régimen en Iracema. Uma Transe Amazónica

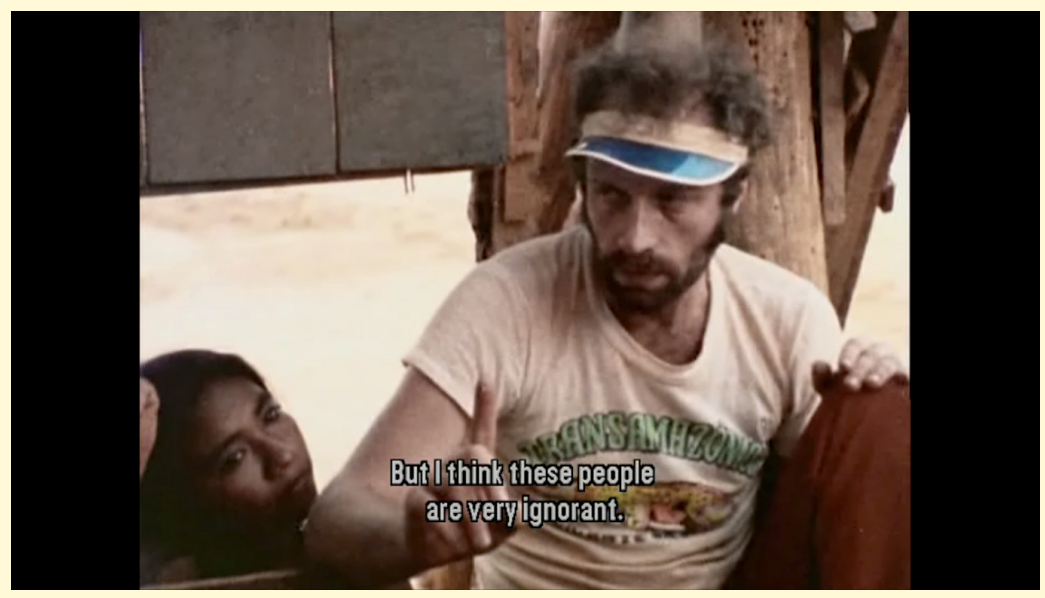

Fonte: Iracema. Uma Transe Amazónica. 
Las raras veces en las que abre la boca, su compañero la trata con desdén y la llama “estúpida”, por lo cual rápidamente vuelve a callarse. Solo cuando él se harta de su compañía y decide expulsarla de su camión, protesta de manera vehemente pero no tiene ningún efecto; al final de la película vuelve a encontrarse con Tião por casualidad, sobreviviendo como prostituta en la ruta. Su cuerpo está tan gastado que Tião apenas la reconoce y la rechaza con asco. Este cuerpo, al igual que el silencio de Iracema a lo largo de las conversaciones, implica una contextualización crítica de la actitud y los propósitos del camionero, y a través de él, de la dictadura militar.

El mutismo también puede afectar a los protagonistas mismos, que pueden ser particularmente taciturnos durante sus viajes. Se puede pensar en ejemplos como Japón (Carlos Reygadas, 2002), Liverpool (Lisandro Alonso, 2008) o Los viajes del viento (Ciro Guerra, 2009) - películas donde el silencio del protagonista se enmarca en una estética de cine de festival, que crea un ambiente enigmático y activa las facultades interpretativas del espectador. En tales casos no hay cuestión de un verdadero encuentro con otro - las películas reflejan más bien el carácter introvertido del protagonista. Durante los encuentros que sí se producen en otras road movies latinoamericanas, se advierten principalmente dos maneras de tratar el idioma, que - tomadas conjuntamente - reflejan la ambivalencia de la lengua como instrumento de comunicación. Estas maneras son el "multilingüismo" y el "translingüismo".

\section{Multilingüismo}

Tal como aparece en el género de la road movie, la modalidad del multilingüismo parte del reconocimiento de la diferencia lingüística entre dos o más personajes para luego escenificar un ensayo de comunicación que desembocará finalmente en lo opuesto: la incomunicación. La palabra "incomunicación" no tiene un sentido negativo en este contexto. Más bien apunta a los 
límites con que los personajes se topan cuando intentan encontrar analogías para una palabra en otro idioma. De esto resulta una toma de conciencia acerca de la especificidad de cada lengua y su carácter irremplazable frente a otra. Me referiré a esta idea mediante el término de "particularismo".

Un primer ejemplo se encuentra en la road movie paraguayaargentina Las acacias (Pablo Giorgelli, 2011). Un camionero argentino, quien se dedica a transportar un tipo de madera (acacias) del Paraguay al Sur, recibe la orden del dueño de su empresa de llevar a una mujer paraguaya y a su bebé a Buenos Aires durante su viaje semanal, sin mayores explicaciones. El camionero Rubén se ha acostumbrado a la soledad en su cabina y accede con dificultad, temiendo las molestias que puedan causar un bebé y su mamá durante el viaje. A lo largo del viaje, sin embargo, desaparece poco a poco la irritación inicial que siente con respecto a su pasajera, Jacinta, y son precisamente el bebé y la ternura que provoca en Rubén lo que les acerca. Aunque el camionero y su pasajera se comunican en español, Rubén se da cuenta de que Jacinta también se expresa en guaraní cuando la observa conversando a gusto con algunos compatriotas durante una pausa en el viaje. Curioso (y un poco celoso ya que se trataba de interlocutores masculinos) empieza a preguntarle por palabras en guaraní para saber si es una lengua fácil o difícil. Cuando se informa acerca de la traducción de la palabra "camión” al guaraní, Jacinta primero le explica que el guaraní se sirve de un préstamo del español ya que no existe una palabra totalmente correspondiente para designar el vehículo en el idioma indígena. (fig.3) 
Figura 3: Jacinta le explica a Rubén que algunas palabras en español no se pueden traducir al guaraní en Las acacias

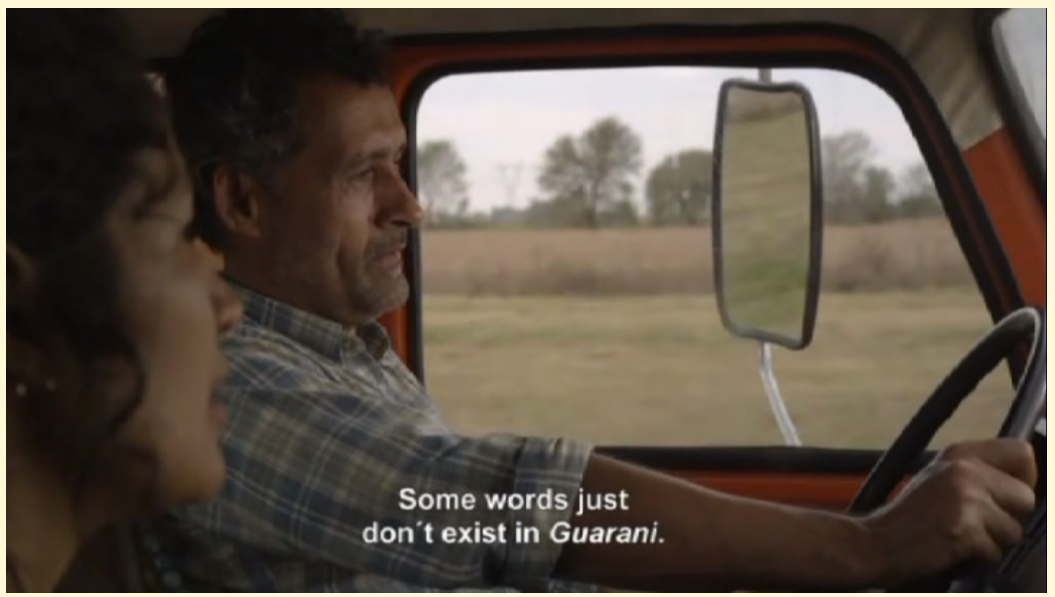

Fonte: Las acacias

Enseguida busca un equivalente proponiendo una expresión que resulta totalmente incomprensible para Rubén cuando la pronuncia ("mba eryru mboguataha"), sugiriendo así la dificultad de medir la congruencia o la falta de congruencia entre el guaraní y el español: bien la palabra no existe, bien resulta totalmente hermética.

Otro ejemplo lo proporciona La jaula de oro (Diego Quemada Díez, 2013), una road movie mexicana que describe el viaje de cuatro menores no acompañados desde Guatemala a Mexicali con el propósito de atravesar la frontera con los Estados Unidos. El viaje lo hacen sentados en la parte superior de los trenes de cargo que llevan al Norte y que, tomados conjuntamente, suelen designarse como "La Bestia". Muchos migrantes indocumentados del Sur se suben a estos trenes sufriendo los peligros y riesgos a los que les exponen unas condiciones de viaje particularmente difíciles: se caen del tren por agotamiento, son asaltados o secuestrados por pandillas, sufren violaciones cuando son mujeres, son detenidos por patrullas que a menudo les roban antes de regresarlos a sus 
países etcétera. En la película solo uno de los cuatro viajeros jóvenes logra finalmente atravesar la frontera - los demás perecen en el camino o poco después del cruce de la frontera. Además de denunciar los peligros que enfrentan los migrantes, la película presta atención a un aspecto poco comentado de estos viajes: la existencia de una diversidad cultural y lingüística en el grupo de viajeros migrantes. Efectivamente, la película se centra en la relación de tensión entre el personaje de Juan, originario de Guatemala, y Chauk, un habitante del Sur de México, que sólo habla tzotzil. Juan da prueba de actitudes racistas con respecto a Chauk, quien pertenece a otro grupo étnico, y a esto se añaden los celos cuando nota que Chauk se lleva relativamente bien con Sara, la novia de Juan, quien también viene de Guatemala. A diferencia de Juan, Sara hace un intento de acercarse a Chauk, lo cual también resulta en un ensayo de traducción de palabras de una lengua a otra. Aprovechando un momento de descanso durante el viaje, Chauk y Sara enseñan el uno al otro palabras de sus idiomas respectivos, sugiriendo el sentido de las palabras mediante gestos ("boca", "ojo", "telaraña"...). Todo marcha perfectamente hasta que Sara se topa con una palabra cuyo sentido no logra adivinar: "taif", lo cual significa "nieve". Aunque Chauk intenta evocar la nieve imitando con sus dedos el movimiento de los copos de nieve revoloteando hacia abajo, Sara es incapaz de imaginarse el sentido de esta palabra, y el juego se interrumpe. De esta manera, la voluntad de acercarse al otro produce primero la ilusión de que se puede lograr una comunicación sin trabas, hasta que la diferencia radical de la otra lengua recupera terreno.

Ahora bien, en ambas películas notamos que las diferencias entre las dos lenguas - la ausencia o el hermetismo de las equivalencias sugeridas - solo surgen a raíz de un acto de comunicación. Los límites de la comunicación no preceden al acto, sino que resultan de él. En ambas películas también forman parte de un acercamiento entre dos personajes que no se interrumpe con el momento de incomunicación. En Las acacias los personajes hacen una cita al final del viaje para salir juntos, en La jaula de oro Sara y Chauk 
siguen siendo amigos hasta que una pandilla elimina a Sara de la historia secuestrándola. Con otras palabras, el momento de incomunicación no implica que fracase la posibilidad de entender al Otro, sino que constituye un elemento natural en un acto de entendimiento mutuo.

\section{Translingüismo}

Si el punto de partida del paradigma del multilingüismo, tal como se da en la road movie, es la comunicación y su resultado final la incomunicación (relativa), el paradigma del translingüismo presenta la variante opuesta. En él se parte de una diferencia radical entre dos lenguas para llegar, paradójicamente, a una comprensión mutua entre los interlocutores. Si el multilingüismo descansaba sobre la idea del carácter irremplazable y único de cada idioma (idea designada mediante el término de "particularismo"), el translingüismo sugiere la posibilidad para la gente de entenderse más allá de las diferencias lingüísticas. Para indicar tal posibilidad y su diferencia con el particularismo, proponemos aquí el término de "universalismo".

El paradigma del translingüismo puede ilustrarse mediante dos películas chilenas. La primera es Música campesina (2011), una counter-road movie de Alberto Fuguet, que relata cómo el personaje principal, Alejandro Tazo, se queda estancado unos días en Nashville después de un viaje fracasado con su novia norteamericana. Nashville es la capital del "country music", y el título de la película refiere a esto, igual que a la dificultad de brindar una traducción literal del nombre de este género. Es evidente que "música campesina" tiene connotaciones bastante diferentes efectivamente de las que tiene "country music". Vagando por las calles de Nashville, demasiado orgulloso como para volver a su país como amante rechazado, Tazo visita a mediados de la película un bar-restaurante o diner donde confiesa sus penas de amor y su miseria de turista sin dinero (le robaron su mochila en el autobús) a una camarera norteamericana.(fig.4) 
Figura 4: Alejandro Tazo confiesa sus problemas a una camarera norteamericana en Música campesina

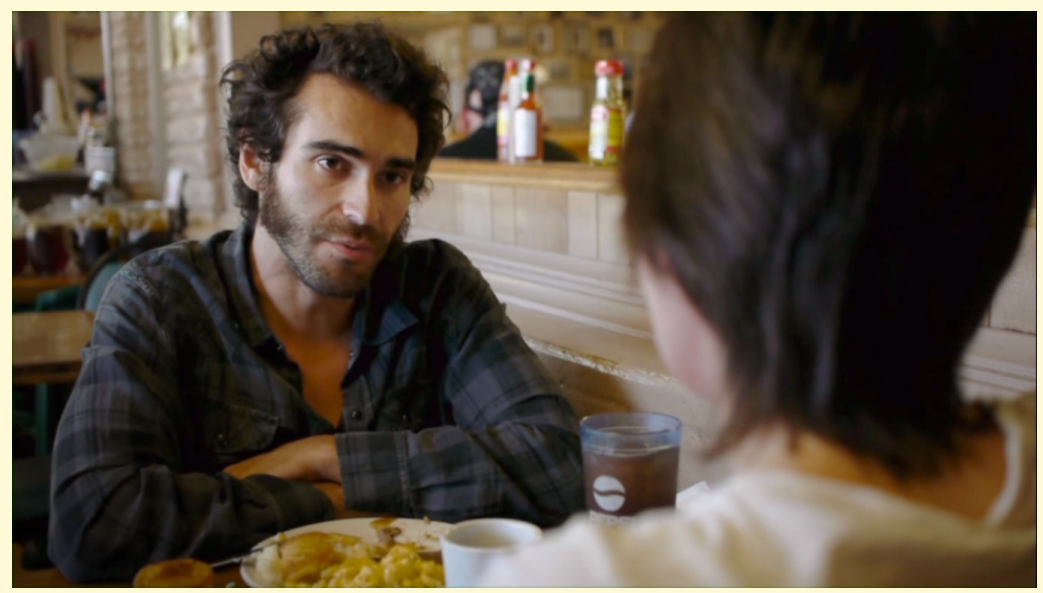

Fonte: Música campesina.

Frustrado por sus numerosos intentos de expresarse en inglés (un idioma que maneja mal), pasa de repente al español, sabiendo que la camarera no domina esta lengua. Hasta se convence de su incapacidad de entenderle proponiéndole algunos enunciados absurdos al que la camarera reacciona de manera profesional, sonriéndole, pero sin dar señales de captar el sentido de sus palabras. Sintiéndose protegido por un idioma que su interlocutora no entiende, Tazo se expresa por primera vez con toda sinceridad acerca de sus problemas sentimentales hasta que ella le irrumpe tomándole la mano en un gesto consolador, y le dice: "I understand, it's gonna be OK". La distancia entre las dos lenguas es plenamente asumida desde el inicio, pero no impide que la camarera entienda que el protagonista se siente profundamente mal y que necesita en ese momento preciso un gesto de afecto y comprensión.

Esta posibilidad de entender al otro en un plano más universal, en el sentido de que prescinda de referencias a particularidades culturales o lingüísticas, se evoca de manera más elocuente todavía 
en Turistas (2009) de Alicia Scherson. En esta película, una turista chilena, Carla, queda plantada por su marido en el camino después de una pelea. Esperando el autobús para regresar a Santiago de Chile, Carla conoce a Ulrik, un estudiante noruego que tiene planes de pasar unos días en un parque natural, llamado Siete Tazas. Decide acompañarle unos días aprovechando el tiempo libre que había pensado pasar con su marido. Una noche acampan en medio del bosque y conversan al calor del fogón. En un momento dado, Ulrik le enseña algunas palabras en noruego a Carla ("kalt", por frío, "tent", por carpa). A continuación recita un poema en lengua escandinava (sin traducción en los subtítulos), y el sonido de las palabras, en combinación con vocablos que parecen indicar un "yo" y un "tú", no tardan en crear un ambiente de intimidad entre los dos. De repente, Carla - quien desconoce el noruego -continúa el poema en lo que parece ser la misma lengua escandinava, inspirada por las palabras que acaba de escuchar, y Ulrik las recibe agradecido, sin hacerle preguntas o mostrar el menor asombro. La lengua exótica del noruego no aleja el uno del otro en esta escena, sino que más bien sirve para acercarles, invitándoles a expresarse en un idioma que crea un punto de encuentro imaginario para los que lo usan. No sorprende en este contexto que Carla descubra, unas escenas más tarde, que Ulrik se llama en realidad Miguel y que vive como ella en la capital chilena. Su identidad de noruego ha sido tan fantasmagórica como la lengua inventada por Carla para continuar su poema. Las diferencias culturales y lingüísticas aparecen en esta película en última instancia como relativas. No proporcionan categorías objetivas de pensar al Otro, sino que se ofrecen como invitaciones para pensarse en relación con los demás, configurando nuevos puntos de encuentro más allá de las diferencias lingüísticas.

\section{Epílogo}

En un estudio sobre el concepto de "pueblo" en el cine latinoamericano, Gonzalo Aguilar afirma que el cine militante de 
los años sesenta cedió el paso, a partir de los noventa, a un nuevo tipo de cine político. Si el cine de los sesenta había implicado un nosotros unificador o "enunciado mayestático" (Aguilar 193), el de los noventa empezó a interesarse por "el encuentro de diversas miradas, voces y posiciones que difieren entre sí” (193). Al privilegiar el momento de encuentro con el Otro, las road movies latinoamericanas se inscriben plenamente en esta reflexión más amplia sobre el pueblo, destacando su diversidad interna y abogando por un reconocimiento de las diferencias imborrables entre las culturas (y las lenguas) que componen la gran familia latinoamericana, es decir, de sus particularidades insuperables. Al mismo tiempo, sin embargo, el nuevo contexto de la globalización ha incrementado la pluralidad de idiomas presentes en el continente, enfrentando el español o el portugués ya no solamente con el quechua o el guaraní, sino también con el noruego o el inglés. Llama la atención que la exploración del potencial simbólico de estas otras lenguas tienda más a la evocación de una idea de universalidad, en la que las diferencias lingüísticas se relativizan o constituyen los puntos de partida de un encuentro más profundo, que trasciende el nivel verbal. En esta segunda variante el concepto de "pueblo" se diluye al coincidir con el de humanidad.

Un examen más extenso de la relación entre lengua y road movie debe indicar si el encuentro con el Otro siempre produce una toma de conciencia acerca de su particularidad cuando hay cuestión de un idioma indígena, mientras que el enfrentamiento con lenguas más "globales" conduciría al planteamiento de una universalidad. Lo que es cierto, por ahora, es que tanto el multilingüismo como el translingüismo ilustran la ambivalencia de la comunicación humana e interpersonal, apuntando a sus límites en el mismo momento en que dos hablantes intentan entenderse mutuamente (multilingüismo), o sugiriendo que podemos entendernos más allá de las diferencias lingüísticas que nos separan (translingüismo). En este sentido, la road movie se convierte en un género de exploración no solamente de espacios geográficos desconocidos, sino del acto comunicativo en sí. 


\section{Referencias}

Aguilar, Gonzalo. Más allá del pueblo: Imágenes, indicios y políticas del cine. México: Fondo de Cultura Económica, 2015.

Bael, Sophia. Brazil Under Construction: Fiction and Public Works. New YorkBasingstoke: Palgrave-Macmillan, 2013.

Bertelsen, Martin. Roadmovies und Western: Ein Vergleich zur Genre-Bestimming des Roadmovies. Hamburg: LIT. Verlag, 1991.

Brandellero, Sara (Ed.). The Brazilian Road Movie: Journeys of (Self)Discovery. Cardiff: University of Wales Press, 2013.

Cohan, Steven; Rae Hark; Ina (Eds.). The Road Movie Book. London-New York: Routledge, 1997.

Duarte, José; Corrigan, Timothy (Eds.). The Global Road Movie: Alternative Journeys around the World. Bristol: Intellect, 2018.

Garibotto, Verónica; Perez; Jorge (Eds.). The Latin American Road Movie. New York: Palgrave Macmillan, 2016.

Gott, Michael; Schiltz, Thibault. Open Roads, Closed Borders: The Contemporary French-Language Road Movie. Bristol-Chicago: Intellect-The University of Chicago Press, 2013.

Laderman, David. Driving Visions: Exploring the road movie. Austin: University of Texas Press, 2002, 334p.

Lie, Nadia. The Latin American (Counter-)Road Movie and Ambivalent Modernity. New York: Palgrave Macmillan, 2017.

Moser, Walter (Ed.) "Le road movie interculturel". Revue d'Etudes Cinématographiques/Journal of Film Studies. 18, Special issue of Cinéma. nos. 2-3 (Spring): 9-30, (2008): 250. 
Orgeron, Devin. Road Movies: From Muybridge and Méliès to Lynch and Kiarostami. New York \& Basingstoke: Palgrave-Macmillan, 2008.

Pinazza, Natália. Journeys in Argentine and Brazilian Cinema: Road Films in a Global Era. New York-Basingstoke: Palgrave-Macmillan, 2014.

Salles, Walter. "Notes for a Theory of the Road Movie". New York Times. 11,(2007): 66-70.

Recebido em: $27 / 02 / 2020$

Aceito em: 28/04/2020

Publicado em julho de 2020

Nadia Lie. E-mail: nadia.lie@kuleuven.be. ORCID: https://orcid.org/00000001-7131-8938 